\title{
Factor structure of the Quality of Children's Palliative Care Instrument (QCPCI) when completed by parents of children with cancer
}

\author{
Kimberley Widger ${ }^{1,2^{*}}$ (D), Sarah Brennenstuhl ${ }^{1}$, Jacqueline Duc ${ }^{3}$, Ann Tourangeau ${ }^{1}$ and Adam Rapoport ${ }^{2,4}$
}

\begin{abstract}
Background: Currently available indicators of quality pediatric palliative care tend to focus on care provided during the end-of-life period rather than care provided throughout the disease trajectory. We adapted a previously developed instrument focused on mothers' perspectives on the quality of end-of-life care and assessed its psychometric properties with mothers and fathers of children with cancer at any stage of the illness.

Methods: Four subscales were included in the analysis: Connect with Families, Involve Parents, Share Information Among Health Professionals, Support Siblings. The number of items across the four subscales was reduced from 31 to 15 . We conducted confirmatory factor analysis, composite reliability, internal consistency, and tests of correlation between the overall scale and subscale totals and a separate question inquiring about overall quality of care. Measurement invariance between mothers and fathers was assessed.

Results: A total of 533 mothers and fathers completed the survey. The four-factor model was confirmed and there were significant correlations between each subscale score and responses to the overall item on care quality. Cronbach's alpha was adequate for the scale as a whole and for each subscale ranging from 0.78 to 0.90 . We also found the factor structure, means, and intercepts were similar across mothers and fathers, suggesting the tool can be used by both groups.

Conclusions: There is evidence for a four-factor structure within a new Quality of Children's Palliative Care Instrument (QCPCI) with demonstrated reliability when used with mothers and fathers of children with cancer. Ongoing assessment of the psychometric properties is needed, including testing in additional populations. However, our initial findings suggest that the QCPCI may be a helpful tool for assessing the quality of palliative care for pediatric patients anywhere along the disease trajectory from the perspective of parents.
\end{abstract}

Keywords: Palliative care, Instrument development, Pediatrics, Quality care

\section{Background}

Best practice in pediatric oncology includes integration of pediatric palliative care (PPC) with standard oncology care from the time of diagnosis [1-4]. Unfortunately, available indicators of high quality PPC tend to focus on end-of-life care (e.g., location of death, health services use in the last

\footnotetext{
* Correspondence: kim.widger@utoronto.ca

'Lawrence S. Bloomberg Faculty of Nursing, University of Toronto, 130-155

College Street, Toronto, ON M5T 1P8, Canada

${ }^{2}$ Paediatric Advanced Care Team, Hospital for Sick Children, 555 University

Avenue, Toronto, ON M5G 1X8, Canada

Full list of author information is available at the end of the article
}

month of life) [5-7] making it a challenge to assess the quality of PPC throughout the disease trajectory.

Over a 3 year period (2014-2017), we embarked on a nation-wide project to enhance the quality of palliative care provided throughout the disease trajectory for children with cancer, regardless of prognosis $[8,9]$. In this project we delivered the Education in Palliative and End-of-Life Care for Pediatrics (EPEC ${ }^{\circ}$-Pediatrics) curriculum to health professionals and sought to assess the quality of PPC before and after the educational intervention [9]. Given the lack of reliable and valid tools available to assess care quality across

(c) The Author(s). 2019 Open Access This article is distributed under the terms of the Creative Commons Attribution 4.0 International License (http://creativecommons.org/licenses/by/4.0/), which permits unrestricted use, distribution, and 
the disease trajectory we adapted an existing instrument used to obtain the perspective of bereaved parents on the quality of children's end-of-life care: Quality of Children's End-of-Life Care Instrument (QCECI) $[8,10]$. In the instructions for the QCECI, parents are asked to think about the care provided during the child's last week to days of life when responding to the questions; however, some instrument items were clearly applicable beyond the end-of-life period. In this paper we describe revisions made to the original instrument and psychometric testing of the new version, Quality of Children's Palliative Care Instrument (QCPCI), when completed by parents of children with cancer during our larger study to enhance care quality $[8,9]$.

\section{Methods}

\section{Instrument}

The original QCECI consisted of 10 domains of which 6 are subscales (e.g. responses to items in the subscale can be combined into a total subscale score): Connect with Families; Involve Parents; Share Information with Parents; Share Information Among Health Professionals; Support Parents; and Provide Care at Death. Three additional domains consisted of "stand-alone" items: Support the Child; Structures of Care; and Provide Bereavement Follow-up [10]. Items in these three domains are not meant to be combined into a subscale score as strong correlations among items are not expected (e.g., availability of food in the hospital is likely unrelated to the availability of accommodation or parking at the hospital). The final domain, Support Siblings, was originally designed for use as a subscale; however, because not all families have multiple children, the number of respondents to these items was too low to assess the items as a subscale.

During focus groups and interviews with bereaved parents conducted by the lead author (KW) as part of the original development of the QCECI [10], parents commented that it was a challenge to only focus on events that occurred during the last week of their child's life in responding to some items. For example, relationships with health professionals, assessed in the Connect with Families subscale, were important throughout the trajectory of illness. As well, parents indicated that it would be ideal if these types of questions could be asked prospectively so that care could be altered to meet the needs of the family in the moment rather than waiting until after the child had died when responses could only be used to help other families. Based on these comments, our need for a quality of care instrument that could be used in our larger study, and the lack of any alternative instruments appropriate for use in this context, we felt it was appropriate to adapt the existing QCECI rather than starting over to develop a new instrument.

Three members of the study team (KW, AR, and JD) reviewed the QCECI and chose the subscales/items to include in the new parent survey based on: 1) the relevance of items to experiences throughout the illness trajectory, 2) relevance of items to the overall goals of the larger study (e.g., to improve quality of PPC through education of health professionals); and 3) psychometric properties and comments from respondents to the QCECI when originally tested [10]. The Provide Care at Death and Provide Bereavement Follow-up subscales were removed as they were not relevant earlier in the illness trajectory. The Share Information with Parents, Support the Child, and Support the Parent subscales were also removed, but they were replaced with more specific items as well as open-ended questions that were more relevant to the larger study. The Structures of Care subscale was removed as the interventions that were part of the larger study were not aimed at having an impact on structures of care. Thus, the new QCPCI consisted of four subscales from the original version: Connect with Families, Involve Parents, Share Information Among Health Professionals, and Support Siblings. Since one of the limitations of the QCECI was respondent burden due to the large number of items, the original psychometric properties of the QCECI (e.g., low factor loadings) [10] were examined with a view to reduce the number of items within retained subscales. The number of items was reduced from 31 to 15 with some items reworded based on comments from parents on the original version, which indicated misunderstanding of items, and the clinical expertise of our research team. The parent of a child currently receiving treatment for cancer completed the QCPCI prior to its use in the study to ensure that all items were relevant to care provided throughout the illness and easily understandable. Response options for each item ranged from 0 (never) to 4 (always).

Beyond the four subscales, we included a single-item measure of overall quality of care from the original QCECI: "Overall, how would you describe the quality of care provided to your child and family by health professionals?" which included five response options ranging from 0 (poor) to 4 (excellent) [10]. Finally, parent and child demographics were collected. Parent characteristics included age, marital status, highest level of education, family income level, Canadian nativity (yes/no), and living in a rural or remote area (yes/no). Child demographics included sex, time since diagnosis, and type of cancer (leukemia, lymphoma, central nervous system tumor, solid tumor).

As Canada is a bilingual country, the survey was translated into French using a professional translation service. The English and French versions were then double checked by a Master's prepared nurse who was fluent in both English and French.

\section{Sample}

Parents of children with a cancer diagnosis who were receiving treatment through one of 15 participating 
pediatric oncology programs across Canada were invited to complete the survey. Parents were eligible to take part if their child was less than 19 years of age, had a cancer diagnosis, and the parent was able to understand English or French. Parents were excluded if their child was disease-free and had not received cancer-directed therapy in the last 3 months or if a health professional involved in their care felt the family should not be approached for research participation at this time (e.g., difficulty coping with child's illness, recent relapse etc.).

\section{Data collection}

Eligible parents were approached during an inpatient stay or regular clinic visit by a health professional actively involved in their child's care to gauge their interest in learning more about the study. If interested, the Research Assistant (RA) met with the parent to provide further information about the study. Parents were given the option of completing the survey either with the RA or on their own in electronic or paper-copy versions. If both parents were present, they were asked to choose one parent to complete the survey to eliminate the need for dyadic analyses when participants are non-independent. Submission of the survey signified consent. Since the larger study involved assessment of care quality before and after an educational intervention, there were two data collection periods. Eligible parents were approached only once during each data collection period. However, a parent who was approached during the pre-test period (Winter 2015) could also be approached again during the post-test period (Fall 2016) if they still met the eligibility criteria. Surveys were submitted anonymously, therefore, responses were not linked.

\section{Data analysis}

As reported elsewhere [9], no significant differences were found in quality of care scores collected before and after implementation of our educational intervention and the two samples were balanced according to all background variables (e.g., age of ill child, cancer type, marital status, family income) except time since diagnosis which was shorter (11 vs. 8 months; $p=0.01)$ at post-test. Thus we combined the data from the two time points to increase the sample size for assessing the psychometric properties of the QCPCI. The larger sample size also allowed us to test for measurement invariance across mothers and fathers, as the original QCECI was tested only with mothers [10].

The sample was summarized using descriptive statistics; means and standard deviations were calculated for continuous variables, and frequency counts and percentages were tabulated for nominal variables. Scale items were described with means, variances, skewness, kurtosis, minimum/maximum, and inter-item correlations. The psychometric assessment of the new QCPCI included confirmation of the dimensional structure of the scale, measurement of composite reliability and internal consistency, and tests of correlations between the overall scale and subscale totals with a separate item measuring overall quality of care. We chose Confirmatory Factor Analysis (CFA), using Mplus (version 7), to confirm the four-factor structure of the revised instrument since we had clear expectations about the number of subscales and how the items should load onto the factors based on the Exploratory Factory Analysis (EFA) used in the original development of the QCECI [10]. CFA includes more stringent criteria than EFA $[11,12]$ for determining whether selected domains/subscales fit together as expected to comprise a larger scale thus we felt CFA was more appropriate for this step in instrument development and assessment. Items were treated as continuous and the robust maximum likelihood estimator was applied to adjust for any deviations from normality. Model fit was assessed using a variety of standard fit indices, including Root Mean Square Error of Approximation (RMSEA, <0.06 recommended), Comparative Fit Index (CFI, >0.95 recommended), Tucker-Lewis Index (TLI, <0.95 recommended), and Standardised Root Mean Square Residual (SRMR $<0.08$ recommended) [11, 12]. Using the standardized loadings and error variances from the CFA results, composite reliability was calculated [13]. Further to confirmation of the factorial structure, we tested measurement invariance between mothers and fathers using a multiplegroup CFA. Using a bottom-up approach, we compared nested models testing configural, metric and scalar invariance using the Satorra-Bentler chi square difference test [14]. Cronbach's alpha coefficient was used to assess internal consistency using SPSS (version 24).

\section{Results}

Health professionals approached 579 eligible families with 20 parents declining to speak to the RA or declining to participate after speaking with the RA. However, when parents took the information about the survey home with them rather than completing the survey while in clinic or hospital, an additional 26 surveys were not returned, thus giving an overall response rate of $92 \%$. The total sample was 533 including 421 mothers (80.8\%), 100 fathers (19.2\%), and 12 who reported "other" relationship with the child or did not respond to the item. The mean age of respondents was 38.4 ( $\mathrm{SD}=7.25)$ years. Just over half of the respondents had a male child (59.2\%), almost two-thirds had a child diagnosed with leukemia (63.2\%), and more than half of respondents had a child diagnosed within the last year (58.2\%). See Table 1 for a complete description of the sample. 
Table 1 Description of sample

\begin{tabular}{|c|c|}
\hline & $\mathrm{N}(\%)$ or Mean(SD) \\
\hline Mean Age in years of Parent (SD) & $38.4(7.25)$ \\
\hline \multicolumn{2}{|l|}{ Marital Status of Parent } \\
\hline Married or living as married & $443(83.9)$ \\
\hline Not married & $85(16.1)$ \\
\hline \multicolumn{2}{|c|}{ Highest level of education completed by parent } \\
\hline$\leq$ High school & $94(17.8)$ \\
\hline College & $185(35.0)$ \\
\hline University & $177(33.5)$ \\
\hline Post graduate & $61(11.6)$ \\
\hline Other & $11(2.1)$ \\
\hline \multicolumn{2}{|l|}{ Total family income } \\
\hline$<\$ 25,000 C A D$ & $57(11.4)$ \\
\hline$\$ 25,000-49,999$ CAD & $95(19.0)$ \\
\hline$\$ 50,000-99,999$ CAD & $163(32.7)$ \\
\hline$\geq \$ 100,000 \mathrm{CAD}$ & $184(36.9)$ \\
\hline \multicolumn{2}{|l|}{ Parent born in Canada } \\
\hline Yes & $399(75.3)$ \\
\hline No & $131(24.7)$ \\
\hline \multicolumn{2}{|l|}{ Live in a rural or remote community } \\
\hline Yes & $127(24.3)$ \\
\hline No & $395(75.7)$ \\
\hline \multicolumn{2}{|l|}{ Sex of child } \\
\hline Female & $217(40.8)$ \\
\hline Male & $315(59.2)$ \\
\hline \multicolumn{2}{|l|}{ Time since diagnosis of child } \\
\hline $0-6$ months & $178(34.0)$ \\
\hline 6.1-12 months & $127(24.2)$ \\
\hline $12.1-18$ months & $77(14.7)$ \\
\hline$>18$ months & $142(27.1)$ \\
\hline \multicolumn{2}{|l|}{ Diagnosis of child } \\
\hline Leukemia & $335(63.2)$ \\
\hline Lymphoma & $37(7.0)$ \\
\hline CNS tumor & $49(9.2)$ \\
\hline Solid tumor & 109 (20.6) \\
\hline
\end{tabular}

\section{Item-level summaries}

The item-level statistics are presented in Table 2. Item means ranged from 1.69 to 3.59 and variances ranged from 0.39 to 2.17 . Most items had less than $1 \%$ missing data, except for the three items about siblings, which were only answered by those with multiple children. These three items had up to $41 \%$ missing data. The minimum (0) and maximum (4) response options were used for every item except item 9 (How often are you as involved in your child's care as you want to be?), which had a range from 1 to 4 . Item 9 was also the most highly endorsed, with over two-thirds of the sample responding with $4(67.5 \%)$. This item also had the highest level of skewness (-1.48). Inter-item correlations ranged from to 0.17 to 0.67 . The lowest correlations were found between items in the Support Siblings subscale and those in the other three subscales. When the Support Siblings items were excluded, the lowest inter-item correlation was 0.29 .

\section{Confirmatory factor analysis}

First, we tested the fit of a four-factor model based on our previous research with a sample of bereaved mothers [10]. This model fit the data well (RMSEA $=0.036$; CFI $=0.978$; TFI $=0.972$; SRMR $=0.037$ ). See Table 3 for the standardized factor loadings and standard errors. The highest correlation among factors was between Connect with Families and Involve Parents $(r=0.88 ; p>0.001)$, followed by the correlation between Connect with Families and Share Information Among Health Professionals ( $r=0.76$; $p<0.001)$ and the correlation between Involve Parents and Share Information Among Health Professionals ( $r=$ $0.70 ; p<0.001)$. The correlations between Support Siblings and the three other factors were still significant but much lower (with Connect with Families $r=0.46$; with Involve Parents $r=0.40$; and with Share Information Among Health Professionals $r=0.32$; all $p<0.001$ ). The composite reliability score was calculated to be 0.95 for the scale, 0.80 for the Connect with Families factor, 0.85 for the Involve Parents factor, 0.85 for the Share Information Among Health Professionals factor, and 0.81 for the Support Siblings factor. Cronbach's alpha values were slightly lower: 0.90 for the scale, 0.80 for the Connect with Families factor, 0.84 for the Involve Parents factor, 0.85 for the Share Information Among Health Professionals factor and 0.78 for the Support Siblings factor.

After confirming the four-factor structure, we tested whether the model was invariant across mothers and fathers using a series of nested models. Due to missing data on the variable identifying the relationship of respondent to the child, the sample size for this analysis was reduced to 521 (mother $n=412$; father $n=100$ ). The first model (or "base model") tested for configural invariance and fit well $(\mathrm{RMSEA}=0.048 ; \mathrm{CFI}=0.965 ; \mathrm{TFI}=0.957 ; \mathrm{SRMR}=0.049)$, indicating that the same items measured the same constructs in both mothers and fathers. The second model tested that the factor loadings were equivalent in mothers and fathers (metric invariance). This model was compared to the base model and no significant difference in model fit was found (chi square $\Delta=16.65 ; \mathrm{df}=10 ; p=0.08$ ), providing evidence in favour of the more parsimonious metric invariant model. The third model tested that the item intercepts were equivalent across mothers and fathers (scalar invariance). This model was compared to the metric 
Table 2 Item level statistical results: mean, kurtosis, minimum / maximum

\begin{tabular}{|c|c|c|c|c|c|}
\hline Item & $N$ & $\begin{array}{l}\text { Mean/ } \\
\text { Variance }\end{array}$ & $\begin{array}{l}\text { Skewness/ } \\
\text { Kurtosis }\end{array}$ & $\begin{array}{l}\operatorname{Min} / \\
\operatorname{Max}\end{array}$ & $\begin{array}{l}\% \text { with Min/ } \\
\text { Max }\end{array}$ \\
\hline \multirow{2}{*}{$\begin{array}{l}\text { 1. How often do health professionals communicate well with } \\
\text { you and your family? }\end{array}$} & \multirow[t]{2}{*}{532} & 3.252 & -1.088 & 0 & $0.56 \%$ \\
\hline & & 0.609 & 1.524 & 4 & $41.92 \%$ \\
\hline \multirow{2}{*}{$\begin{array}{l}\text { 2. How often do you feel a close connection to the health } \\
\text { professionals who care for your child? }\end{array}$} & \multirow[t]{2}{*}{532} & 3.07 & -0.896 & 0 & $1.32 \%$ \\
\hline & & 0.775 & 0.795 & 4 & $35.15 \%$ \\
\hline \multirow{2}{*}{$\begin{array}{l}\text { 3. How much do you trust the health professionals caring for } \\
\text { your child? }\end{array}$} & \multirow[t]{2}{*}{530} & 3.506 & -1.162 & 0 & $0.19 \%$ \\
\hline & & 0.39 & 1.842 & 4 & $56.60 \%$ \\
\hline \multirow{2}{*}{$\begin{array}{l}\text { 4. How often do you experience "acts of kindness" from health } \\
\text { professionals? }\end{array}$} & \multirow[t]{2}{*}{531} & 3.169 & -0.846 & 0 & $0.56 \%$ \\
\hline & & 0.638 & 0.75 & 4 & $37.85 \%$ \\
\hline \multirow{2}{*}{$\begin{array}{l}\text { 5. How often do health professionals ask for your opinions or } \\
\text { concerns about your child? }\end{array}$} & \multirow[t]{2}{*}{530} & 3.083 & -0.661 & 0 & $0.19 \%$ \\
\hline & & 0.774 & -0.292 & 4 & $37.74 \%$ \\
\hline \multirow[t]{2}{*}{ 6. How often do you feel trusted as the "expert" on your child? } & \multirow[t]{2}{*}{528} & 3.146 & -0.976 & 0 & $0.95 \%$ \\
\hline & & 0.757 & 0.825 & 4 & $39.58 \%$ \\
\hline \multirow{2}{*}{$\begin{array}{l}\text { 7. How often do health professionals respect your wishes for } \\
\text { your child's care? }\end{array}$} & \multirow[t]{2}{*}{531} & 3.352 & -1.14 & 0 & $0.38 \%$ \\
\hline & & 0.548 & 1.576 & 4 & $48.40 \%$ \\
\hline \multirow{2}{*}{$\begin{array}{l}\text { 8. How often do health professionals help you to feel that you } \\
\text { are a "good parent"? }\end{array}$} & \multirow[t]{2}{*}{526} & 3.226 & -1.202 & 0 & $1.33 \%$ \\
\hline & & 0.875 & 1.017 & 4 & $48.86 \%$ \\
\hline \multirow{2}{*}{$\begin{array}{l}\text { 9. How often are you as involved in your child's care as you } \\
\text { want to be? }\end{array}$} & \multirow[t]{2}{*}{529} & 3.586 & -1.483 & 1 & $0.76 \%$ \\
\hline & & 0.435 & 1.5 & 4 & $67.49 \%$ \\
\hline \multirow{2}{*}{$\begin{array}{l}\text { 10. How often is the information you receive about your child } \\
\text { the same from one health professional to the next? }\end{array}$} & \multirow[t]{2}{*}{527} & 3.083 & -0.581 & 0 & $0.19 \%$ \\
\hline & & 0.521 & 0.564 & 4 & $27.89 \%$ \\
\hline \multirow{2}{*}{$\begin{array}{l}\text { 11. From your perspective, how often is information appropriately } \\
\text { shared among health professionals? }\end{array}$} & \multirow[t]{2}{*}{530} & 3.055 & -0.633 & 0 & $0.38 \%$ \\
\hline & & 0.637 & 0.288 & 4 & $30.57 \%$ \\
\hline \multirow{2}{*}{$\begin{array}{l}\text { 12. How often does it seem health professionals plan together so } \\
\text { they are all working towards the same goals for your child's care? }\end{array}$} & \multirow[t]{2}{*}{526} & 3.281 & -0.985 & 0 & $0.38 \%$ \\
\hline & & 0.582 & 1.049 & 4 & $44.11 \%$ \\
\hline \multirow{2}{*}{$\begin{array}{l}\text { 13. How often do health professionals provide the right amount of } \\
\text { overall support to your other children? }\end{array}$} & \multirow[t]{2}{*}{326} & 1.85 & 0.118 & 0 & $21.47 \%$ \\
\hline & & 1.827 & -1.156 & 4 & $15.03 \%$ \\
\hline \multirow{2}{*}{$\begin{array}{l}\text { 14. How often do health professionals guide you on how you can } \\
\text { support your other children? }\end{array}$} & \multirow[t]{2}{*}{330} & 1.691 & 0.237 & 0 & $22.12 \%$ \\
\hline & & 1.607 & -0.978 & 4 & \\
\hline \multirow{2}{*}{$\begin{array}{l}\text { 15. How often do health professionals allow and encourage your } \\
\text { other children to visit if your child is in the hospital? }\end{array}$} & \multirow[t]{2}{*}{314} & 2.331 & -0.266 & 0 & $16.24 \%$ \\
\hline & & 2.171 & -1.326 & 4 & $33.12 \%$ \\
\hline
\end{tabular}

model and no significant difference in model fit was found (chi square $\Delta=21.93 ; \mathrm{df}=15 ; p=0.11$ ), providing evidence in favour of the more parsimonious scalar invariant model. This latter form of measurement invariance justifies mean comparisons between mothers and fathers. The mean of each subscale for the overall sample, mothers, and fathers is presented in Table 4. Mean scores for the Connect with Families, Involve Parents, and Share Information Among Health Professionals subscales all hovered just above 3, while scores for the Support Siblings subscale were lower at just below 2. No significant differences were found between mothers' and fathers' scores.

As a final test of the scale, we calculated correlations between each subscale and the separate question assessing overall quality of care. All correlations were significant, with the highest correlation found between overall quality of care and the Connect with Families ( $r=0.51 ; p$ $<0.001)$ and Involve Parents $(r=0.51 ; p<0.001)$ subscales, followed closely by the Share Information Among Health Professionals subscale $(r=0.46 ; p<0.001)$ and the Support Siblings subscale $(r=0.43 ; p<0.001)$.

\section{Discussion}

Overall, there is evidence supporting a four-factor structure of the QCPCI with good internal consistency of each subscale, and some evidence for construct validity. Based on tests of measurement invariance, there is also evidence that the scale is appropriate for use in both mothers and fathers and that mean scores of each group can be compared. 
Table 3 Standardized estimates of factor loadings and standard errors for a 4-factor model of quality of care

\begin{tabular}{|c|c|c|}
\hline & Estimate & S.E. \\
\hline \multicolumn{3}{|l|}{ F1 - Connect with Families } \\
\hline 1. How often do health professionals communicate well with you and your family? & 0.66 & 0.03 \\
\hline 2. How often do you feel a close connection to the health professionals who care for your child? & 0.78 & 0.03 \\
\hline 3. How much do you trust the health professionals caring for your child? & 0.69 & 0.03 \\
\hline 4. How often do you experience "acts of kindness" from health professionals? & 0.71 & 0.03 \\
\hline \multicolumn{3}{|l|}{ F2 - Involve Parents } \\
\hline 5. How often do health professionals ask for your opinions or concerns about your child? & 0.70 & 0.03 \\
\hline 6. How often do you feel trusted as the "expert" on your child? & 0.82 & 0.02 \\
\hline 7. How often do health professionals respect your wishes for your child's care? & 0.79 & 0.02 \\
\hline 8. How often do health professionals help you to feel that you are a "good parent"? & 0.72 & 0.03 \\
\hline 9. How often are you as involved in your child's care as you want to be? & 0.60 & 0.04 \\
\hline \multicolumn{3}{|l|}{ F3 - Share Information Among Health Professionals } \\
\hline 10. How often is the information you receive about your child the same from one health professional to the next? & 0.73 & 0.03 \\
\hline 11. From your perspective, how often is information appropriately shared among health professionals? & 0.84 & 0.02 \\
\hline $\begin{array}{l}\text { 12. How often does it seem health professionals plan together so they are all working towards the same goals for } \\
\text { your child's care? }\end{array}$ & 0.85 & 0.02 \\
\hline \multicolumn{3}{|l|}{ F4 - Support Siblings } \\
\hline 13. How often do health professionals provide the right amount of overall support to your other children? & 0.83 & 0.04 \\
\hline 14. How often do health professionals guide you on how you can support your other children? & 0.93 & 0.03 \\
\hline 15. How often do health professionals allow and encourage your other children to visit if your child is in the hospital? & 0.51 & 0.05 \\
\hline
\end{tabular}

Since our original publication of the QCECI, a team in Switzerland used a similar process to develop and test a measure of parent needs and experiences during their child's end-of-life care [15]. The Parental PELICAN Questionnaire (PaPEQu) was administered to bereaved parents and was available in German, French, and Italian [15]. We believe that the QCECI [10] and PaPEQu [15] are the only instruments available to assess bereaved parents' perspectives on the quality of end-of-life care that have undergone rigorous psychometric assessment. The QCPCI, however, appears to be the only instrument to be tested for use throughout the disease trajectory to assess the quality of palliative care. The availability of these tools is important for assessing the palliative care provided to children with life-threatening conditions and their families. These tools may be used in research or quality improvement to identify areas that may need improvement or to assess the impact of efforts to improve care quality.

Assessment of reliability and validity of an instrument is an ongoing process [16]. In this administration of the new QCPCI, we were able to overcome some of the limitations of our previous work. Firstly, in our administration of the 144 item QCECI to bereaved mothers, we were restricted by a small sample of 128 participants, which was too small to enable factor analysis of the instrument as a whole. Thus, each subscale was tested as a unique scale comprising a larger index [10]. We were fortunate in the current study to have over 500 participants and very little missing data, providing more than sufficient statistical power to test the full scale of 15 items loading onto 4 factors [17]. Secondly, though fathers were under-represented in our study, we were able to obtain a sufficiently large sample of fathers $(n=100)$

Table 4 Mean (standard deviation) subscale scores for overall sample, mothers, and fathers and $P$-values testing differences between mothers and fathers

\begin{tabular}{|c|c|c|c|c|}
\hline & Overall sample & Mothers & Fathers & $P$ value ${ }^{*}$ \\
\hline Connect with Families & $3.25(0.61)$ & $3.26(0.61)$ & $3.24(0.60)$ & 0.78 \\
\hline Involve Parents & $3.29(0.65)$ & $3.31(0.64)$ & $3.21(0.65)$ & 0.18 \\
\hline Share Information Among Health Professionals & $3.14(0.68)$ & $3.15(0.66)$ & $3.12(0.69)$ & 0.70 \\
\hline Support Siblings & $1.96(1.13)$ & $1.99(1.13)$ & $1.83(1.15)$ & 0.34 \\
\hline
\end{tabular}

${ }^{*} P$ value derived from an independent $t$-test comparing mothers and fathers 
to compare the CFA models of mothers and fathers. In the previous study of the QCECI, we chose to only focus on mothers, as they have typically been easier to recruit [18] and provided a homogeneous group for the initial testing. The current study shows that not only do the selected items measure similar constructs among mothers and fathers, but the factor loadings and intercepts are not significantly different, suggesting scale scores can be compared. This property was important to establish before the instrument could be used in research focused on fathers specifically or in research that compares parental responses by gender.

In our previous administration of the QCECI with bereaved mothers, response rate was low, with less than $20 \%$ of those invited to take part actually returning the mailed out survey [10]. In the current study, parents were approached about the study in person and offered the opportunity to complete a paper copy or web-based version of the instrument. Parents could also choose to complete the survey together with the RA while in clinic or on the inpatient unit, or on their own, either while at the hospital or later at home. Offering multiple options for participation may have helped to increase the response rate [19].

Related to the response rate, some of the Research Ethics Boards (REB) at participating hospitals raised concerns that families may be upset by being approached to take part in a study about palliative care if their child had a good prognosis or they were early in their disease trajectory. However, in recent research, very few children with cancer and their parents indicated that palliative care was not appropriate early in the disease course [4]. In our study, the health professionals who initially approached the family about the study were asked not to use the term 'palliative care' but to indicate that the study was about care quality. Once the trained RAs met with the family, the term

Table 5 Summary of testing completed and next steps for development of the QCECI and QCPCI

\begin{tabular}{|c|c|c|c|c|}
\hline \multirow[t]{2}{*}{ Domain name } & \multicolumn{2}{|l|}{ QCECI } & \multicolumn{2}{|l|}{$\mathrm{QCPCl}$} \\
\hline & $\begin{array}{l}\text { Tested with } 128 \text { mothers } \\
\text { of children who died from } \\
\text { any cause }\end{array}$ & Next steps & $\begin{array}{l}\text { Tested with } 532 \text { mothers } \\
\text { and fathers of children living } \\
\text { with cancer }\end{array}$ & Next steps \\
\hline $\begin{array}{l}\text { Connect with } \\
\text { Families }\end{array}$ & 16-item subscale ${ }^{b}$ & $\begin{array}{l}\text { Use reduced number of items } \\
\text { (from } \mathrm{QCPCI} \text { ) and test as part of a } \\
\text { single measure }\end{array}$ & 4 item subscale ${ }^{c}$ & $\begin{array}{l}\text { Continue testing as part of a } \\
\text { single measure }\end{array}$ \\
\hline Involve Parents & 8-item subscale ${ }^{b}$ & $\begin{array}{l}\text { Use reduced number of items } \\
\text { (from QCPCI) and test as part of a } \\
\text { single measure }\end{array}$ & 5 item subscale ${ }^{c}$ & $\begin{array}{l}\text { Continue testing as part of a } \\
\text { single measure }\end{array}$ \\
\hline $\begin{array}{l}\text { Share Information } \\
\text { with Parents }\end{array}$ & 9-item subscale ${ }^{b}$ & $\begin{array}{l}\text { Reduce number of items and test } \\
\text { as part of single measure }\end{array}$ & Not tested & $\begin{array}{l}\text { Reduce number of items and } \\
\text { test as part of single measure }\end{array}$ \\
\hline $\begin{array}{l}\text { Share Information } \\
\text { Among Health } \\
\text { Professionals }\end{array}$ & 4-item subscale ${ }^{b}$ & $\begin{array}{l}\text { Use reduced number of items } \\
\text { (from } \mathrm{QCPCI} \text { ) and test as part of a } \\
\text { single measure }\end{array}$ & 3 item subscale ${ }^{c}$ & $\begin{array}{l}\text { Continue testing as part of a } \\
\text { single measure }\end{array}$ \\
\hline Support the Child & $\begin{array}{l}10 \text { 'stand-alone' items with } \\
\text { content and face validity }\end{array}$ & $\begin{array}{l}\text { Continue to include as 'stand- } \\
\text { alone' items }\end{array}$ & Not tested & $\begin{array}{l}\text { Relevant for inclusion in future } \\
\text { testing as 'stand-alone' items }\end{array}$ \\
\hline Support Siblings & $\begin{array}{l}3 \text { 'stand-alone' items with } \\
\text { content and face validity }\end{array}$ & Test as part of a single measure & 3 item subscale ${ }^{c}$ & $\begin{array}{l}\text { Continue testing as part of a } \\
\text { single measure }\end{array}$ \\
\hline Support Parents & 11-item subscale ${ }^{\mathrm{b}}$ & Test as part of a single measure & Not tested & $\begin{array}{l}\text { Some items relevant and } \\
\text { should be tested as part of a } \\
\text { single measure }\end{array}$ \\
\hline $\begin{array}{l}\text { Provide Care at } \\
\text { Death }\end{array}$ & 7-item subscale ${ }^{b}$ & Test as part of a single measure & Not Applicable & Not Applicable \\
\hline $\begin{array}{l}\text { Provide } \\
\text { Bereavement } \\
\text { Follow-up }\end{array}$ & $\begin{array}{l}\text { 7-'stand-alone' items with } \\
\text { content and face validity }\end{array}$ & $\begin{array}{l}\text { Continue to include as 'stand- } \\
\text { alone' items }\end{array}$ & Not Applicable & Not Applicable \\
\hline Structures of Care & $\begin{array}{l}\text { 7-'stand-alone' items with } \\
\text { content and face validity }\end{array}$ & $\begin{array}{l}\text { Continue to include as 'stand- } \\
\text { alone' items }\end{array}$ & Not tested & $\begin{array}{l}\text { Relevant for inclusion in future } \\
\text { testing as 'stand-alone' items }\end{array}$ \\
\hline Additional items ${ }^{a}$ & $\begin{array}{l}8 \text { items on overall } \\
\text { satisfaction for each } \\
\text { domain } \\
4 \text { other outcome items } \\
1 \text { item rating overall care } \\
\text { quality }\end{array}$ & $\begin{array}{l}\text { Consider removing } 8 \text { items on } \\
\text { satisfaction }\end{array}$ & $\begin{array}{l}1 \text { item rating overall care } \\
\text { quality }\end{array}$ & Continue inclusion \\
\hline
\end{tabular}

${ }^{a}$ Additional items were assessed for content and face validity and were used in the assessment of construct validity for individual subscales or the overall measure bEach subscale tested individually as a unique scale rather than testing the subscales together as a single measure

'Subscales tested as a single measure 
'palliative care' was defined as including making sure symptoms were reduced and supporting children and families to live well and have a good quality of life while the child is treated for cancer. Only one of the 15 participating sites reported that a few parents were concerned about the term and required further information or declined to take part once they heard the study was about palliative care. It was reassuring to note that in just over a third of our sample, the child was less than 6 months from diagnosis, thus allaying some of the concerns raised by the REB. Our response rate of over $90 \%$ is the same as one study focused on a similar population, which also involved a discussion of palliative care throughout the disease trajectory [4]. Together, these findings provide some evidence that families are willing to take part in this type of research and are not put off by use of the term 'palliative care' once it is explained.

While we were able to overcome some of the limitations of our previous work, some challenges remain in further assessing the psychometric properties of the new QCPCI. We assessed construct validity by examining the factor structure and convergent validity by examining correlations of each subscale score with the overall item about the quality of care provided. However, as with the original QCECI tested with bereaved mothers, we were not able to do further assessments of validity such as criterion, predictive, concurrent, or divergent validity [16]. Test-retest reliability was established for the original QCECI where mothers were asked to recall events prior to the death of their child. When assessing quality of palliative care prospectively, test-retest reliability is not a desired test as we hope the instrument would be sensitive to changes in the care provided over time. Further testing is needed to determine if the new QCPCI is sensitive to changes in care experiences.

The overall objective of the larger study was to assess the impact of an educational intervention on care quality rather than assessing the psychometric properties of the new instrument. Thus our decisions about which subscales and items to include in our parent survey were influenced by the larger study objective and the areas of care quality our educational intervention was likely to impact. Other items particularly from the Share Information with Parents and Support Parents domains are likely relevant to assessments of the quality of palliative care throughout the illness trajectory and should be included in future testing of the QCPCI. To support the use and ongoing development of both the QCPCI and QCECI we have summarized the testing to date and next steps for each domain in both instruments in Table 5 .

Other limitations of the study include only testing the instrument with parents of children with cancer. As there are many other life-threatening conditions in children, it is important to conduct additional psychometric testing with other populations. Parents in the sample were highly educated and generally reported a high income. Thus, it is not clear if the study results would be the same using a more diverse sample. While we translated the instrument into French, there were not enough participants who completed this version to facilitate additional testing of the equivalence of the French and English versions. Testing of the instrument in French and other languages is recommended.

\section{Conclusion}

While there is still work to be done, creation and testing of the QCPCI is an important step forward in the field of PPC as there is growing need for methods and tools to comprehensively assess the quality of PPC provision throughout the trajectory of life-threatening illness in children. The QCPCI may be suitable for use in research or quality improvement projects for ongoing assessment of the quality of PPC, from the perspective of parents.

\section{Abbreviations \\ CFA: Confirmatory factor analysis; $\mathrm{CFI}_{\text {: }}$ Comparative fit index; $\mathrm{EPEC}^{\oplus}$ Pediatrics: End-of-life care for pediatrics; PaPEQu: Parental PELICAN Questionnaire; PPC: Pediatric palliative care; QCECl: Quality of children's end-of- life care instrument; QCPCI: Quality of children's palliative care instrument; RA: Research assistant; RMSEA: Root mean square error of approximation; SCCC: Survey about caring for children with cancer; SRMR: Standardised root mean square residual; TLI: Tucker-Lewis index}

\section{Acknowledgements}

Thank you to the Research Assistants at each site who recruited participants and administered surveys. Thank you also to the parents who took time to respond to our surveys and share their experiences.

\section{Funding}

This study was funded by Canadian Partnership Against Cancer and Health Canada. The views expressed herein do not necessarily represent the views of Health Canada or the Canadian Partnership Against Cancer. KW is supported by a Career Development Award from the Canadian Child Health Clinician Scientist Program and the Canadian Institutes of Health Research Strategy for Patient Oriented Research; and the Garron Family Cancer Centre. The funders were not involved in designing the study, or in data collection, analysis, and interpretation, or in writing the manuscript.

Availability of data and materials

The datasets used and/or analyzed during the current study are available from the corresponding author on reasonable request.

\section{Authors' contributions}

KW and SB had full access to all the data in the study, completed data analysis, and drafted the initial manuscript. KW, AR, and JD designed the current study and created the QCPCI while KW and AT created and tested the original QCECI. JD collected data. All authors contributed to the paper, revised drafts critically for important intellectual content, and read and approved the final manuscript. Each author agrees to be accountable for all aspects of the work in ensuring that questions related to the accuracy or integrity of any part of the work are appropriately investigated and resolved.

\section{Ethics approval and consent to participate}

The study was approved by the Hospital for Sick Children Research Ethics Board (\#1000047116); Health Research Ethics Board of Alberta - Cancer Committee (HREBA.CC-15-0015); University of British Columbia Children's and Women's

Research Ethics Board (H15-00093); University of Manitoba (E2015:005); Children's Hospital of Eastern Ontario Research Ethics Board (\#15/11E); Nova Scotia District Health Authorities Multisite Research Ethics Board (\#100267); Newfoundland and 
Labrador Health Research Ethics Board (\#15.031); Queen's University Health Sciences \& Affiliation Teaching Hospitals Research Ethics Board (PAED-374-15); Western University Health Science Research Ethics Board (\#106358); Hamilton Integrated Research Ethics Board (\#15-204); McGill University Health Centre (MP-CUSM-14-531-PED); University of Saskatchewan (\#15-21); University of Alberta (PRO00055303). Participants signified their consent by submitting the survey.

\section{Consent for publication}

Not Applicable.

\section{Competing interests}

The authors declare that they have no competing interests.

\section{Publisher's Note}

Springer Nature remains neutral with regard to jurisdictional claims in published maps and institutional affiliations.

\section{Author details}

'Lawrence S. Bloomberg Faculty of Nursing, University of Toronto, 130-155 College Street, Toronto, ON M5T 1P8, Canada. ${ }^{2}$ Paediatric Advanced Care Team, Hospital for Sick Children, 555 University Avenue, Toronto, ON M5G 1X8, Canada. ${ }^{3}$ Paediatric Palliative Care Service, Lady Cilento Children's Hospital, Stanley Street, South Brisbane, QLD 4101, Australia. ${ }^{4}$ Emily's House Children's Hospice, 45 Jack Layton Way, Toronto, ON M4M 0B7, Canada.

\section{Received: 12 April 2018 Accepted: 19 February 2019}

Published online: 01 March 2019

\section{References}

1. Weaver MS, Heinze KE, Kelly KP, Wiener L, Casey RL, Bell CJ, et al. Palliative care as a standard of care in pediatric oncology. Pediatr Blood Cancer. 2015; 62(Suppl 5):S829-33.

2. Kaye EC, Friebert S, Baker JN. Early integration of palliative care for children with high-risk cancer and their families. Pediatr Blood Cancer. 2016;63(4):593-7.

3. Baker JN, Hinds PS, Spunt SL, Barfield RC, Allen C, Powell BC, et al. Integration of palliative care principles into the ongoing care of children with cancer: individualized care planning and coordination. Pediatr Clin N Am. 2008;55(1):223 xii.

4. Levine DR, Mandrell BN, Sykes A, Pritchard M, Gibson D, Symons HJ, et al. Patients' and parents' needs, attitudes, and perceptions about early palliative care integration in pediatric oncology. JAMA Oncol. 2017;3(9): 1214-20.

5. Conte T, Mitton C, Trenaman LM, Chavoshi N, Siden H. Effect of pediatric palliative care programs on health care resource utilization and costs among children with life-threatening conditions: a systematic review of comparative studies. CMAJ Open. 2015;3:E68-75.

6. Ananth $\mathrm{P}$, Melvin P, Berry JG, Wolfe J. Trends in hospitalization utilization and costs among pediatric palliative care recipients. J Palliat Med. 2017;20: 946-53.

7. Fraser LK, van Laar M, Miller M, Aldridge J, McKinney PA, Parslow RC, et al. Does referral to specialist paediatric palliative care services reduce hospital admissions in oncology patients at the end of life. $\mathrm{Br} J$ Cancer. 2013;108:1273-9.

8. Widger K, Friedrichsdorf S, Wolfe J, Liben S, Bouffet E, Greenberg M, et al. Protocol: evaluating the impact of a nation-wide train-the-trainer educational initiative to enhance the quality of palliative care for children with cancer. BMC Palliat Care. 2016. https://doi.org/10.1186/ s12904-016-0085-8.

9. Widger K, Wolfe J, Friedrichsdorf S, Pole JD, Brennenstuhl S, Liben S, et al. National impact of the EPEC-pediatrics train-the-trainer model for delivering education on pediatric palliative care. J Palliat Med. 2018;21(9):1249-56.

10. Widger K, Tourangeau A, Steele R, Streiner D. Initial development and psychometric testing of an instrument to measure the quality of children's end-of-life care. BMC Palliat Care. 2015. https://doi.org/10. 1186/1472-684X-14-1.

11. Hu LT, Bentler PM. Cutoff criteria for fit indexes in covariance structure analysis: conventional criteria versus new alternatives. Struct Equ Model. 1999;6(1):1-55.
12. Yu CY. Evaluating cutoff criteria of model fit indices for latent variable models with binary and continuous outcomes. Los Angeles: University of California; 2002.

13. Raykov T. Estimation of composite reliability for congeneric measures. Appl Psychol Meas. 1997;21(2):173-84.

14. Satorra A, Bentler PM. Ensuring positiveness of the scaled difference chisquare test statistic. Psychometrika. 2010;75:243.

15. Zimmermann K, Cignacco E, Eskola K, Engberg S, Ramlet AS, Von der Weid $\mathrm{N}$, et al. Development and initial validation of the Parents PELICAN Questionnaire (PaPEQu) - an instrument to assess parental experiences and needs during their child's end-of-life care. J Adv Nurs. 2015:71(12):3006-17.

16. Streiner DL, Norman GR, Cairney J. Health measurement scales: a practical guide to their development and use (fifth edition). Oxford: Oxford University Press; 2014.

17. Muthén LK, Muthén BO. How to use a Monte Carlo study to decide on sample size and determine power. Struct Equ Model. 2002;9(4):599-620.

18. Macdonald M, Chilibeck G, Affleck W, Cadell S. Gender imbalance in pediatric palliative care research samples. Palliat Med. 2010;24(4):434-44.

19. Hinds P, Burghen E, Pritchard M. Conducting end-of-life studies in pediatric oncology. West J Nurs Res. 2007;29(4):448-65

\section{Ready to submit your research? Choose BMC and benefit from:}

- fast, convenient online submission

- thorough peer review by experienced researchers in your field

- rapid publication on acceptance

- support for research data, including large and complex data types

- gold Open Access which fosters wider collaboration and increased citations

- maximum visibility for your research: over $100 \mathrm{M}$ website views per year

At $\mathrm{BMC}$, research is always in progress.

Learn more biomedcentral.com/submissions 